\title{
Disabled Population
}

National Cancer Institute

\section{Source}

National Cancer Institute. Disabled Population. NCI Thesaurus. Code C16661.

Groups with similar restrictions or lack or ability to perform physical or mental activities in a manner or within the range considered normal for a human being. 